\title{
System Dynamic Modeling for Plastic Supply Chain in Klang Valley, Malaysia
}

\author{
Jenny Ong ${ }^{1,3}$, Siti Nurmaya Musa², Noor Zalina Mahmood ${ }^{1 *}$ \\ ${ }^{1}$ Institute of Biological Sciences, Universiti Malaya, Malaysia \\ ${ }^{2}$ Faculty of Engineering, Universiti Malaya, Malaysia \\ ${ }^{3}$ Infrastructure Geo-hazards and Sustainable Materials (IGSM), Faculty of Engineering, \\ Built Environment \& Information Technology, SEGi University, Malaysia
}

Received: 6 July 2021

Accepted: 10 September 2021

\begin{abstract}
Plastic packaging wastes are increasing due to the COVID-19 pandemic as consumers tend to stay home and purchase online. Plastic packaging waste is difficult to break down. It pollutes the environment and then enters the food chain, putting people and wildlife at risk. This paper presents the development of system dynamic models for sustainable plastic supply chain management in Klang Valley, Malaysia. System dynamic models for plastic supply chains, including forward, open-loop and closed-loop supply chains, were developed using Vensim 7.2 PLE software. To estimate the amount of plastic packaging wastes discharged at landfill, these models were simulated using various waste diversion rates. The results indicated that, when all stakeholders in the supply chain recycled $10 \%$ of their plastic packaging waste, the total amount of plastic packaging waste going to landfill could be reduced by approximately $65 \%$. However, the means of open-loop and closed-loop supply chains, did not differ much.
\end{abstract}

Keywords: sustainable supply chain management, plastic packaging wastes, stock and flow diagram

\section{Introduction}

Plastics have unique characteristics such as can be easily molded into different shapes, high strength-toweight ratio, excellent thermal properties, electrical insulation, and resistance to acids, alkalis, and solvents [1]. Therefore, plastics are used in wide application such as packaging, clothing, toys, household, and industries products, as well as construction materials such as pipes, window frame, floor coverings, roofing sheets and cables [1, 2]. Moreover, the use of plastic

e-mail: alin@um.edu.my materials has prevailed over other man-made materials such as metal, glass and paper, particularly for food and beverage packaging purposes [3-5]. Nevertheless, plastics are made from petrochemicals sourced from fossil fuels, which are non-renewable and do not degrade easily. Hence, there is a growing move in the industry towards reuse and reprocessing of plastics for economic and environmental purposes $[1,6,7]$.

Several strategies have been set forth to change the linear nature of industrial system to cyclical system (closed-loop system), which are more environmentally sound and sustainable [8, 9]. In the linear system, natural raw materials are used to make new products. After these products reach its end-of-life stage, it will be disposed of either through landfilling or incineration. 
Whereas in the cyclical system or closed-loop system, available resources are utilized more effectively, and wastes generated are reprocessed to turn into raw materials for another product or processes.

In this research, system dynamics modeling is used to assess the effects of sustainable supply chain management on plastic recovery rate. Studies had been conducted using system dynamics model to optimize recycling, remanufacturing and collection of waste material in supply chain [10-12]. However, these studies only focused on using system dynamic model to measure capacity planning for remanufacturing in closed-loop supply chain management.

In Malaysia, amount of plastic wastes has grown from $9.1 \%$ in 2005 to $13.2 \%$ in 2012 [13, 14]. When China government implemented policy to ban import of unprocessed plastic wastes in January 2018, plastic wastes from developed countries ends up in developing countries such as Malaysia and Indonesia [15-17]. It was reported that the amount of plastic wastes exported to Malaysia has escalated drastically by $260 \%$ to 461,000 tonnes in the first half of 2018 as compared to the first half of 2017, which was 128,000 tonnes [15].

Although studies had been conducted in relation to plastic waste management in Malaysia, research area in sustainable supply chain management using system dynamic model is still lacking. Moreover, there are approximately 500 industrial areas in Malaysia and approximately, 164 of these industrial areas are located in Klang Valley. Therefore, the main objective of this paper is to develop system dynamic models for sustainable supply chain management for plastic wastes in Klang Valley, Malaysia.

Supply chain management is the management of a supply network of interconnected businesses involved in providing the products and services required by the customers [18, 19]. Apart from this, simulation model is used to describe how the complex system works as well as to evaluate the interrelationships between the units in the systems [20]. Thus, topics on supply chain management for plastic industry and system dynamic modeling are discussed in this section.

\section{Plastic Supply Chain Management}

Plastic supply chain can either be linear process or supply-loop process (recycling supply chain). Conventional supply chain management is a linear process, where the flow of materials and information is in forward direction. The flow of materials and materials starts from the procurement of raw materials, transform them into intermediate or final products, and deliver them through a distribution system and ends with final point of consumption [19, 21, 22]. Meanwhile, in the supply loop process, which is also known as sustainable supply chain management, end-of-life products are reprocessed either to replace primary resources in forward supply chain or to produce other new products [23].
The movement of the products from one place to another before reaching the final point of consumption have major social, economy, and environmental implications. Not all products reach the consumers at the end of the supply chain as some were damaged during delivery or expired before purchased by consumers. Supply chains are not sustainable unless they take into accounts all the economy, environmental and social issues [24, 25].

In recent years, more research had been conducted to study the sustainability of supply chain management. Generally, there are two types of sustainable supply chain management for plastic industry, which are closed-loop and open-loop supply chain. Study conducted by Huysman et al. [7] showed that both closed-loop and open-loop plastic recycling are more resource efficient as compared to landfilling and incineration with energy recovery. Furthermore, study has shown that mechanical recycling can be a superior alternative in most environmental aspects as compared to the production of new plastics and composites [6].

In closed-loop recycling, the intrinsic properties of the recycled materials are similar to those of the virgin materials. Therefore, the recycled materials can be used to substitute the virgin materials. However, in openloop recycling, the intrinsic properties of the recycled materials differ from the virgin materials. Thus, these recycled materials are used for other product applications [7, 26].

Some of the challenges faced in plastic wastes recycling are the wide application of plastic materials, use of additives, blends in a multitude of products and presents of contaminants, that can limit the number of times that products can be recycled [3]. Besides that, the demand for recycled resin also depends on the price of virgin materials and the quality of the recycled resin itself. Another challenge faced is that in order to produce controlled specifications of recycled resin at a competitive price in comparison to virgin resins, plastic recyclers require high amount of recycled plastics [1].

At the same time, not all plastics can be recycled, especially thermosets, which are used widely in electronic appliances [1]. Nevertheless, as more research been carried out and with the help of advance technology, certain thermoset plastic which was not recyclable is now recyclable, for example polyurethane [27]. Nevertheless, thermoset plastic waste can also be used for energy recovery whereby, this type of wastes is incinerated to produce heat that is subsequently used to generate electricity.

\section{System Dynamic Modeling}

Models are used to describe how the complex system works as well as to evaluate the interrelationships between the units in the systems [20]. In addition, it also helps to test people's understanding on the behaviors of the system of interest and to forecast the behavior of the system of interest in response to a change in one 
or more of its driving forces [28]. However, models are always less complicated as compared to the original system [29].

Generally, there are two types of modeling, namely, analytical modeling and simulation modeling. Analytical modeling uses spreadsheet (Excel) and mathematical formulas to produce the output while simulation models requires special software tools such as Powersim, Vensim and Anylogic to produce the output. Simulation models have more advantages compare to analytical models when analysing dynamic systems. Even though, analytical model is widely available and easy to use, it is are unable to process dynamic systems that feature nonlinear behaviour, "memory", non-intuitive influences between variables, time and causal dependencies as well as large number of uncertainties and parameters. This is because in most cases, the analytical solution, which is formula-based, is either hard to find or simply doesn't exist [29].

In this research, the simulation model was developed based on system dynamics model. System dynamics is a powerful tool for understanding, analysing and simulating complex systems over time and is often used to analyse policies $[30,31]$. In addition, it also helps to test people's understanding on the behaviours of the system of interest and to forecast the behaviour of the system of interest in response to a change in one or more of its driving forces [28].

In system dynamics modeling, several diagramming tools are used to capture the structure of the system, which include causal loop diagrams and stock and flow maps. At the initial stage, the structure of a system is conceptualized qualitatively through causal loop diagram. Then, it will be analyzed using a quantitative assessment through stock and flow diagram.

Causal loop diagram was used as a preliminary step to create an overview of the system as well as to show how the data flow within the system. It is also known as feedback loop diagram. A causal loop diagram consists of variables connected by arrows (causal link) denoting the causal influences among the variables. Each causal link is assigned to a polarity, which is positive $(+)$ or negative (-) that indicate how the dependent variable changes when the independent variable change. A positive link means that if the cause increases, the effect increases above what it would otherwise have been and if the cause decrease, the effect decreases below what it would have been. As for negative link, it means that if the cause increases, the effect decreases below what it would have been, and if the cause decreases, the effect increases above what it would otherwise have been.

While causal loop diagrams emphasize on the feedback structure of a system, stock and flow diagrams emphasize on the underlying physical structure of the system. Stocks and flows track accumulations of information, material and money as they move through a system. Stocks characterize the system's state and generate the information on which decisions are based.
The decisions then change the flow rates, adjust the stocks and close the system's feedback loops.

The structure of all stock and flow structures is composed of four elements, namely stocks, inflows and outflows, valves and clouds. Stocks are represented by rectangles, inflows and outflows are represented by pipe, valves control the flows and clouds represent the sources and sinks for the flows. In general, the flows will be functions of the stock and other state variables and parameters. Hence, the structure corresponds to the following integral equation:

$$
\operatorname{Stock}(t)=\int_{t_{0}}^{t}[\operatorname{Inflow}(\mathrm{s})-\operatorname{Outflow}(\mathrm{s})] \mathrm{ds}+\operatorname{Stock}\left(t_{0}\right)
$$

As a conclusion, there are three types of supply chain management for plastic industry, namely, forward loop supply chain, open loop supply chain and closed loop supply chain. Both the open loop and closed loop supply chain management are part of sustainable supply chain management. In addition, system dynamic model can be used to understand, analyze, and simulate complex system over time.

\section{Material and Methods}

This section would discuss on the steps involved in developing the model for this research. The following steps are adapted from Sterman [28] and Allenby and Graedel [32]. In addition, field studies were conducted to gather information to verify the conceptual model.

The first step in modeling was problem articulation. According to Sterman [28], for a successful modeling study, the purpose of the model must be clear so that the model built can address the problems faced by the users. To define the problem dynamically, three processes were carried out. These processes were identification of key variables, established reference modes and explicitly fixed the time horizon.

The second step of modeling was formulation of dynamic hypothesis. The process involved development of research framework using causal loop diagram to develope maps of causal structure based on key variables, reference modes and other available data.

The third step in modeling was to convert causal loop diagram into stock and flow diagram. The structure of stock and flow diagram composed of four elements, namely stocks, inflows and outflows, valves and clouds. The stock and flow diagrams were adopted from Vlachos et al. [11], Rodrigues et al. [12] and, Golroudbary and Zahraee [10] whereby system dynamics model was used to measure capacity planning for remanufacturing in closed loop supply chain.

The fourth step of modeling was to test the model. The testing processes includes comparing the simulated behavior of the model to the actual behavior of the system. 
The final step in modeling process was to use the constructed model to design and evaluate policies for improvement. Policy design process was not only changing the values of parameters, it also includes the creation of entirely new strategies, structures and decision rules.

In this study, Vensim PLE 7.2 software was used to construct and run the model. Vensim ${ }^{\circledR}$ is a free simulation software developed by Ventana Systems. Vensim ${ }^{\circledR}$ is a user-friendly software that has been designed to lower the barriers to the beginning system dynamics modeler. It comes with sample model, help engine and Adobe Acrobat format PLE User's Guide. It primarily supports continuous simulation namely system dynamics, with some discrete event and agentbased modeling capabilities.

\section{Results and Discussion}

This section discussed the development of the system dynamics models for forward supply chain, open-loop and closed-loop supply chain and the outcomes from the system dynamics models analysis.

\section{Causal Loop Diagram for Plastic Supply Chain Management}

In the forward plastic supply chain management, the material flow started with the inventory of raw materials which are the plastic resins and ended with disposal of used plastic materials in the landfill, while recycling activities or product returns activities were not considered. The key players in the forward plastic supply chain are manufacturers, retailers and consumers. In addition, the flow rate of the plastic materials in the supply chain was determined by the demand for the plastic materials as well as the order backlog. Fig. 1 depicts the forward plastic supply chain management in Malaysia.

Open-loop supply chain refers to process whereby the recycled materials were mostly used to substitute other materials for other product applications, instead of replacing the virgin materials $[7,26]$. In the plastic manufacturing industries, food grade plastic packaging manufacturers do not use recycled plastic resin in their production line. This is to avoid the risk of contamination of the consumable products. However, they do recycle their plastic wastes either internally or send to plastic recycler to help them to reprocess their plastic wastes to produce non-food grade plastic materials. Fig. 2 shows the supply chain of open loop supply chain.

On the other hand, in the closed-loop supply chain, plastic wastes are recycled to produce non-food grade recycled plastic resins, which were subsequently used to manufacture products such as plastic bags, buttons for clothing and gardening containers. Fig. 3 shown the causal loop diagram for closed loop supply chain.

The following Table 1 presents the definitions of the variables found in forward, open and closed loop supply chain. In addition, the word INTEG used in the formula represent time integral, where variable of integration moves between time 0 to time $t$. Next, the word MAX represent maximum and MIN represent minimum.

\section{Stock and Flow Diagram for Plastic Supply Chain}

Three stock and flow diagrams were constructed to analyse the flow of plastic materials in the supply chain management. It started with the forward flow of plastic materials, then extended to open-loop supply chain and closed-loop supply chain, as shown diagrammatically in Fig. 4, Fig. 5 and Fig. 6 respectively.

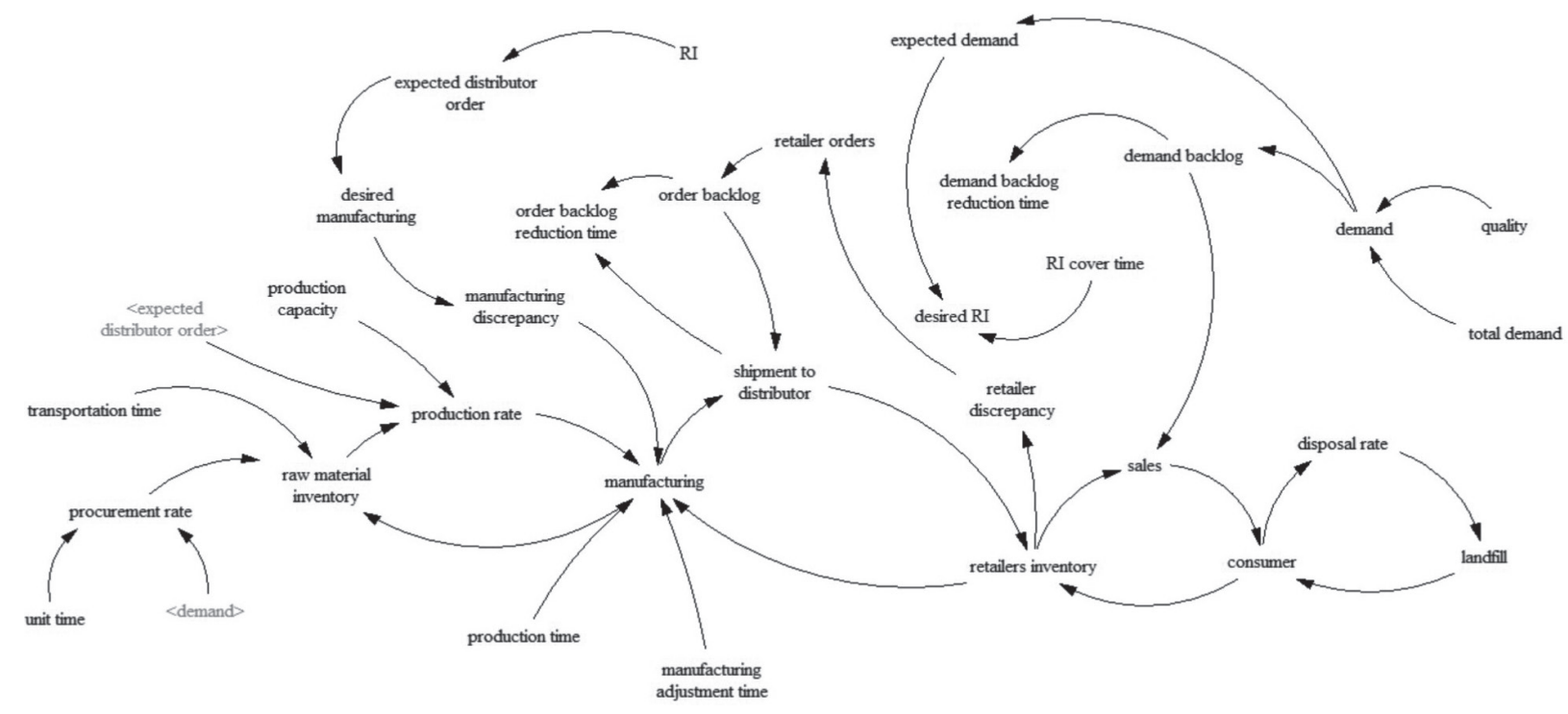

Fig. 1. Causal loop diagram for forward loop plastic supply chain management. 


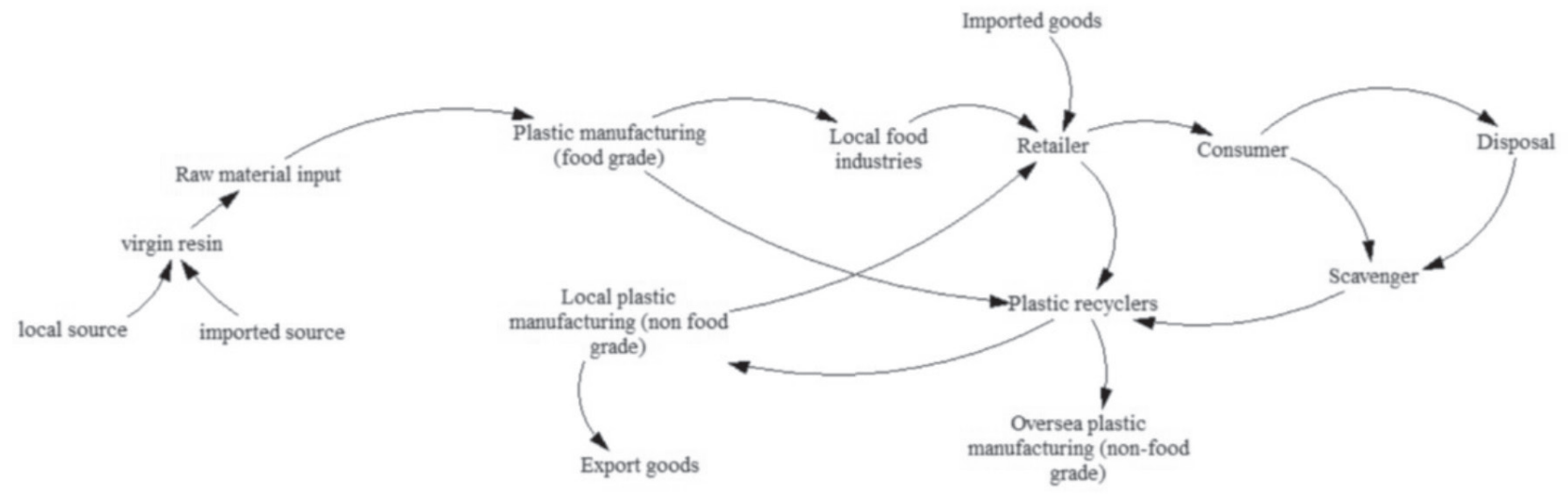

Fig. 2. Causal loop diagram for open loop plastic supply chain management.

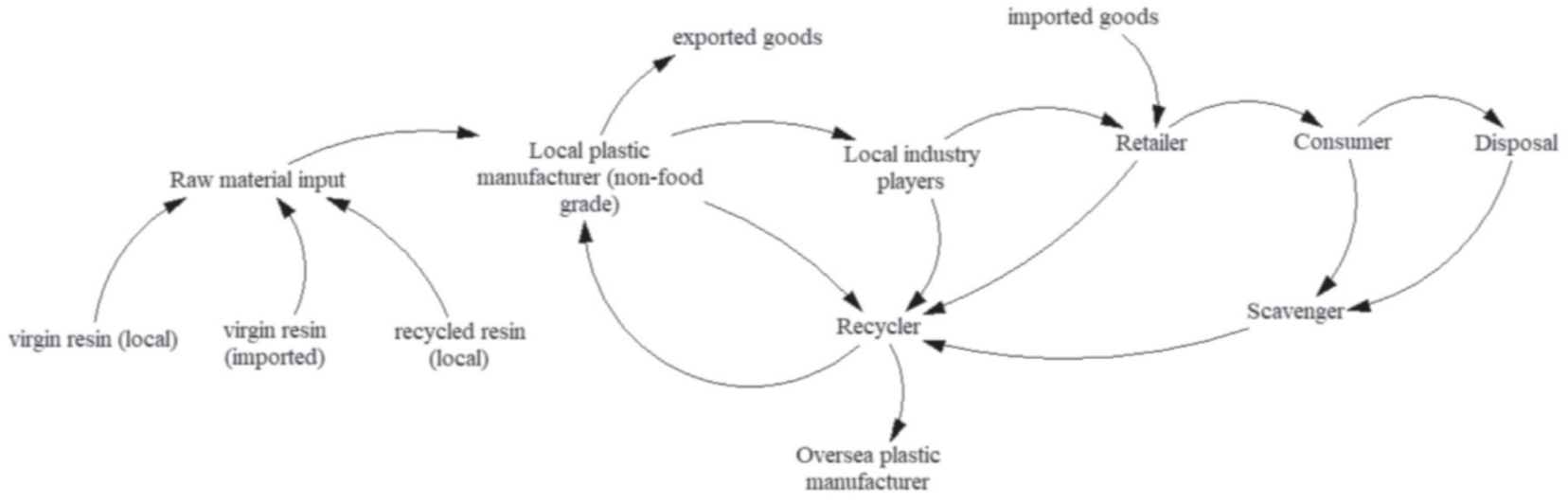

Fig. 3. Causal loop diagram for closed-loop plastic supply chain.

Table 1. Definition of variables found in forward supply chain.

\begin{tabular}{|c|c|c|}
\hline Name & Unit & Definition \\
\hline Raw material inventory & Tonne & Total amount of raw material in stock that are yet to be used \\
\hline Procurement rate & Tonne/week & Procurement of raw material over time taken for transportation \\
\hline Production rate & Tonne/week & Total amount of products produced per week \\
\hline Transportation time & Week & Time taken to deliver the raw materials \\
\hline Manufacturing & Tonne & $\begin{array}{l}\text { Integral of net inflow of production rate minus the net outflow of } \\
\text { shipment to distributors }\end{array}$ \\
\hline Expected distribution order & Tonne/week & Expected time taken to distribute products based on order received \\
\hline Manufacturing discrepancy & Tonne & $\begin{array}{c}\begin{array}{c}\text { Difference between the desired manufacturing and the expected } \\
\text { distributor order }\end{array}\end{array}$ \\
\hline Manufacturing adj time & Week & Time frame to keep the manufacturing line with the desired level \\
\hline Retailer inventory (RI) & Tonne & Integral of the net inflow of shipment to distributors minus the sales \\
\hline Sales & Tonne/week & $\begin{array}{l}\text { Time needed to deliver the products to customers from the time of } \\
\text { receiving the orders }\end{array}$ \\
\hline Demand backlog & Tonne & The amount of customer demand that cannot be satisfied \\
\hline Demand & Tonne & Total demand for products \\
\hline Demand backlog reduction rate & Tonne/week & Equals to sales \\
\hline Order backlog & Tonne & The amount of customer order that cannot be satisfied \\
\hline
\end{tabular}


Table 1. Continued.

\begin{tabular}{|c|c|c|}
\hline Retailers orders & Tonne/week & The amount of order received from retailers \\
\hline Order backlog reduction time & Tonne/week & Equal to distribution rate \\
\hline Shipment time & Week & Time taken to deliver the products from manufacturer to retailer \\
\hline Deliver time & Week & Time taken to deliver the products from retailer to customer \\
\hline Expected demand & Tonne/week & Delayed in demand per week \\
\hline RI discrepancy & Tonne & Difference in Retailer inventory \\
\hline RI adj time & Week & Adjustment time for Retailer Inventory \\
\hline Quality & Dimensionless & The desired quality of the product \\
\hline Consumer & Tonne & Integral of the net inflow of sales minus the disposal rate \\
\hline Disposal rate & Tonne/week & Estimated time of the products being used before disposed to landfill \\
\hline Disposed time & Week & Time taken to reach landfill \\
\hline Landfill & Tonne & Amount of waste that accumulate in the landfill \\
\hline Used products inventory & Tonne & $\begin{array}{l}\text { Time integral of the net inflow of return product rate minus the net } \\
\text { outflow of accepted products for recycling and rejected products rate }\end{array}$ \\
\hline Accepted products for recycling & Tonne/week & Amount of materials that can be recycled \\
\hline Rejected products rate & Tonne/week & Amount of materials that cannot be recycled \\
\hline Recyclable products & Tonne & Amount of recyclabled products accumulated \\
\hline Inspection time & Week & Time take to determine which materials can be recycle or not \\
\hline Recycling rate & Tonne/week & Time taken to recycle the recyclable materials \\
\hline Manufacturer non food-grade & Tonne & Amount of products yet to be sell at the manufacturer factory \\
\hline Demand for recycled materials & Tonne/week & Amount of recycled materials requested by the customer \\
\hline Recycling efficiency & Dimensionless & Efficiency of recycling plant \\
\hline Recycling time & Week & Time taken to recycle the used products \\
\hline Recycling capacity & Tonne/week & The amount of recyclable produced by the recyclers \\
\hline Demand for recycled materials & Tonne/week & Total demand for recycled materials per week \\
\hline Export demand & Tonne & Total amount of product requested by oversea customer \\
\hline Local demand & Tonne & Total amount of product requested by local customer \\
\hline Demand time & Week & Customer ordering time \\
\hline Used packaging manufacturing & Tonne & Amount of recyclable collected from manufacturers \\
\hline Used packaging retail & Tonne & Amount of recyclable collected from retailers \\
\hline Used packaging consumer & Tonne & Amount of recyclable collected from consumers \\
\hline Used packaging landfill & Tonne & Amount of recyclable collected from landfill \\
\hline
\end{tabular}

In these models, the material flow started with the inventory of raw materials, which are the plastic resins. However, all these three models have different end points. The end point for forward supply chain and closed supply chain is the landfill while there are two end points for open supply chain which are the landfill and the manufacturer for non-food grade plastics. In addition, in Fig. 5 and Fig. 6, the box with dotted line represented the sustainable supply chain management intervention.
Both the open-loop supply chain and closed-loop supply chain models were built based on the same foundation as the forward flow supply chain and were extended to include sustainable supply chain management (SSCM) intervention such as plastic recovery and recycling processes. The following assumptions were considered when the simulation models were constructed:

- The only recovery activity that the open-loop supply chain and closed-loop supply chain develops is recycling. 
- There is no production backlog in the production process.

- 240 months (from year 2010 to 2030) is considered for time duration of simulation.

- Demand backlog at initial time is considered zero.

- Order backlog at initial time is considered zero.

The forward supply chain model was formulated to account for input of raw materials, production rate, shipment time, customer demand and order backlogs, sales and disposal rate to the landfill, as indicated in Fig. 4. Plastic waste recovery and recycling was excluded in this model.

The primary inputs to the raw material inventory was procurement rate of plastic resin, which depends on the customer demand, availability of raw materials and transportation time. Next, the primary inputs for manufacturing is production rate. Factors that contribute to the production rate were raw material inventory, production capacity, expected distribution order, manufacturing discrepancy, production time and manufacturing adjustment time.

Factors that affect the retailer inventory were shipment to distributor rate, that depends on the manufacturing inventory, shipment time and customer orders backlog. From the retailer inventory, the plastic materials would eventually go to consumer and ends up in the landfill.

Primary inputs for consumption were sales rate, delivery time and demand backlog while input for landfill was disposal rate. Factors that determined the demand backlog were quality perspective index, actual quality, and total demand. While factors that

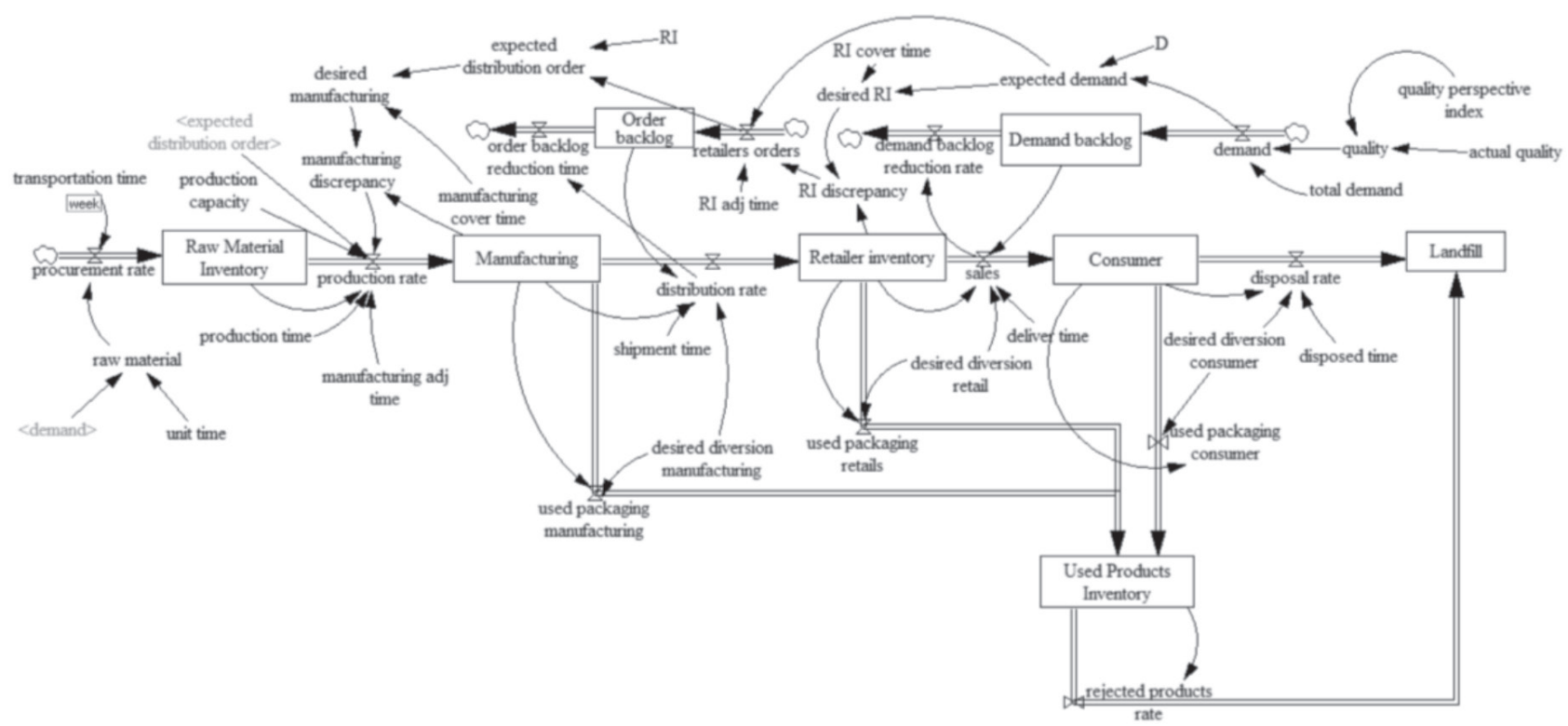

Fig. 4. Stock and flow diagram for forward loop plastic supply chain management.

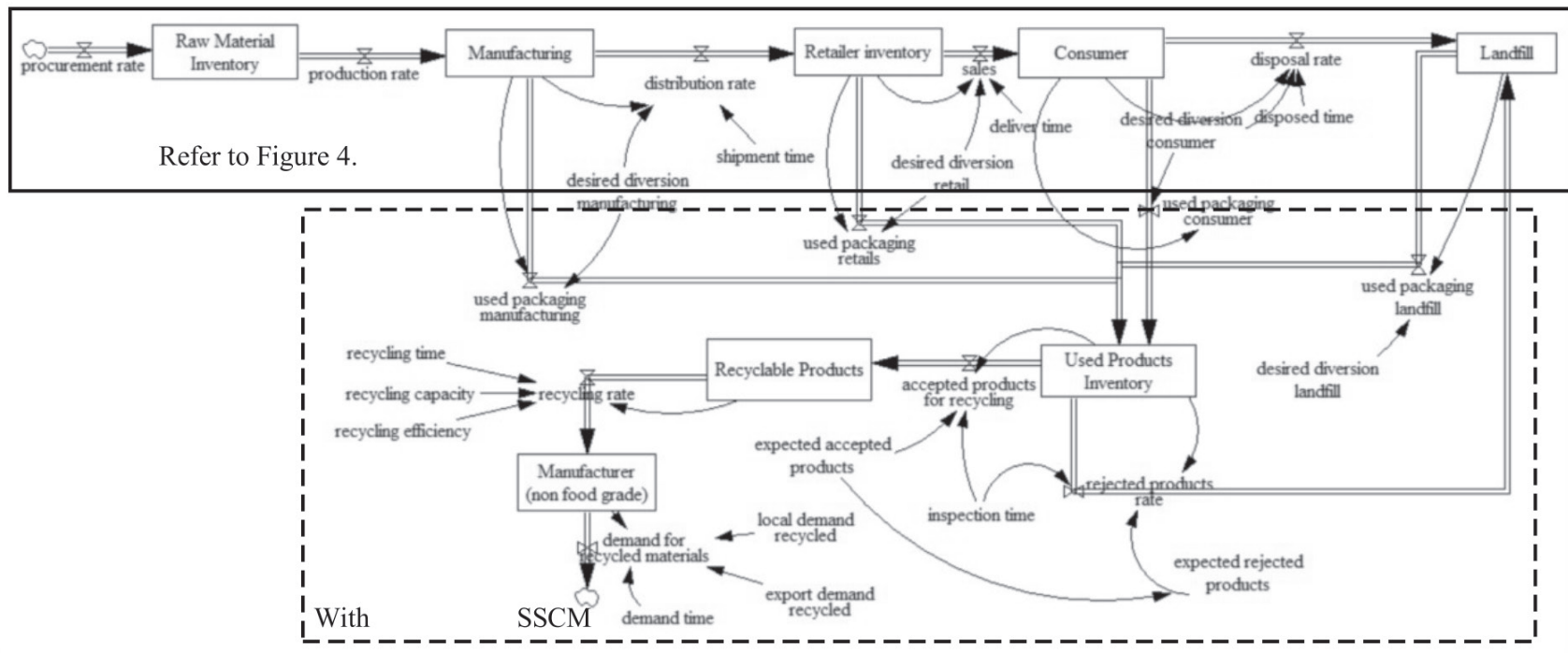

Fig. 5. Stock and flow diagram for open-loop plastic supply chain management. 


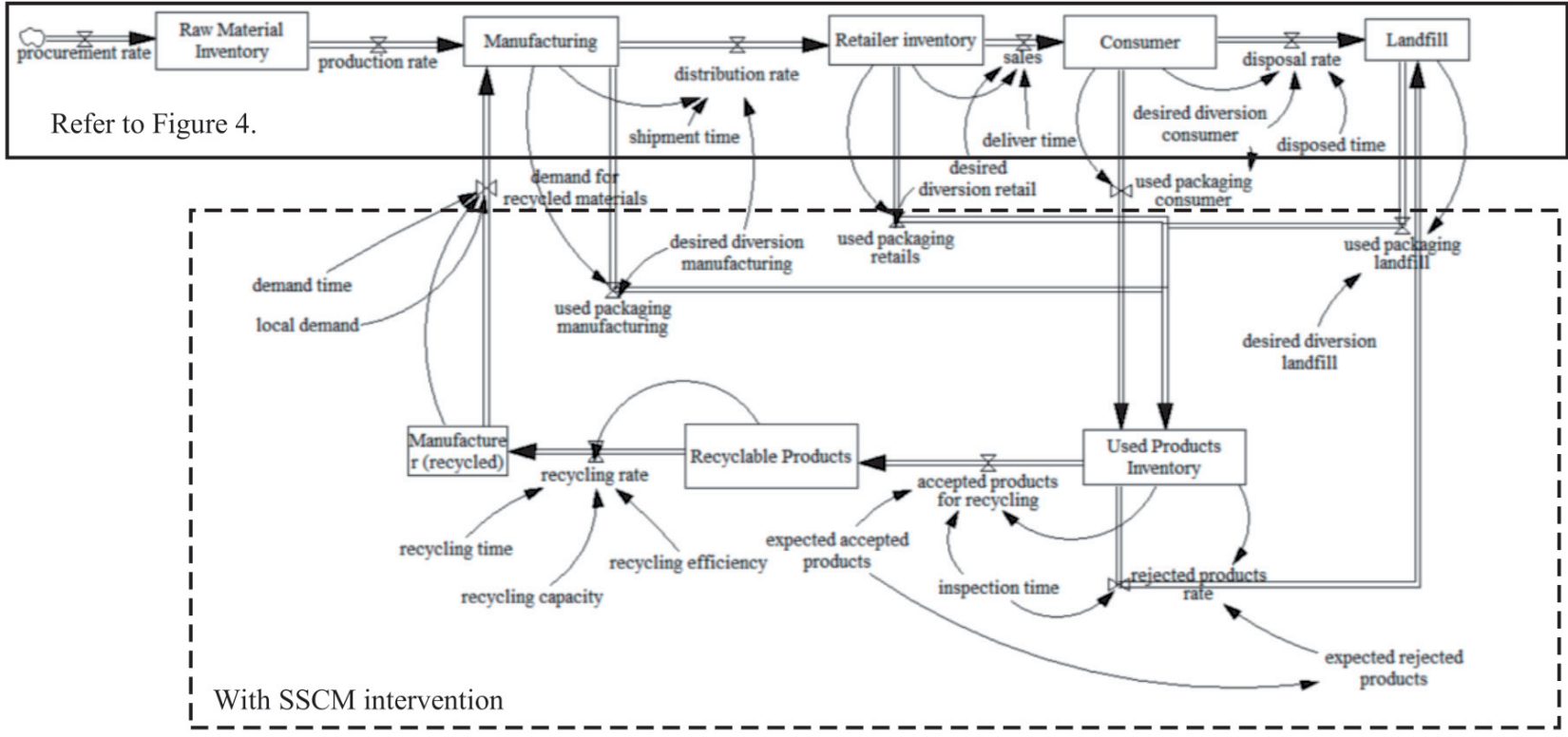

Fig. 6. Stock and flow diagram for closed-loop plastic supply chain management.

determined the order backlogs were input from the retailers' inventory and expected market demand.

The open loop supply chain and closed loop supply chain model has further extended the forward supply chain model to include the recovery of used plastic materials from the manufacturers, retailers, consumers and landfill site, as shown in Fig. 5 and Fig. 6 respectively. The box with dotted line in Fig. 5 and Fig. 6 represented the intervention of sustainable supply chain management (SSCM).

\section{Model Validation}

Model validation involved the assessment of the behaviour and structure of the model in terms of being consistent with the available facts and descriptive knowledge of a real world system [33]. In this study, the validation tests performed referred to dimensional consistency test and behavior reproduction test. Dimensional consistency test involved checking of the left-hand side and the right-hand side of each of the equations of the model. While, behavior reproduction test was used to measure how accurately the simulation model can reproduce the dynamic behavior of the real behaviour of the real system.

Fig. 7 showed the comparison between the simulated and historical behavior of waste going to landfill in Malaysia. The model-simulated waste data at landfill agrees reasonably well with historical behavior, and this indicated that the model could simulate the actual behavior of the system closely and can be used for policy analysis. The model-simulated waste data was generated from the forward supply chain model where recycling activities were excluded.

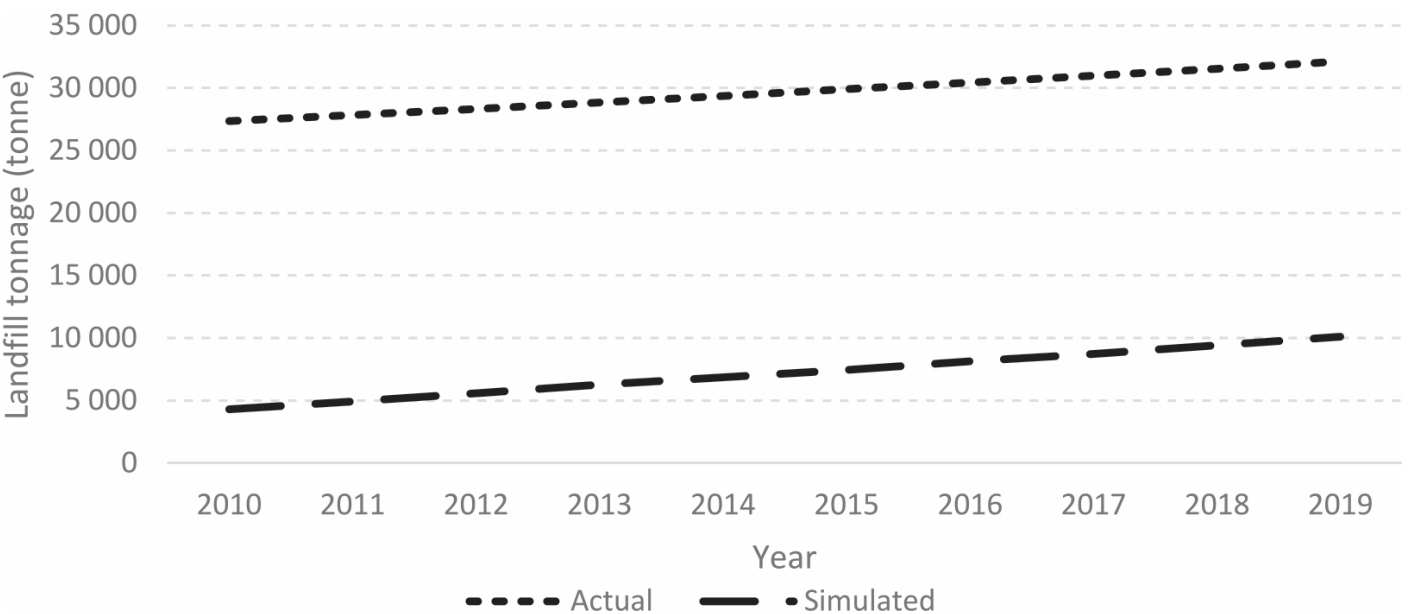

Fig. 7. Comparison between the simulated and actual data of waste going to landfill in Malaysia. 


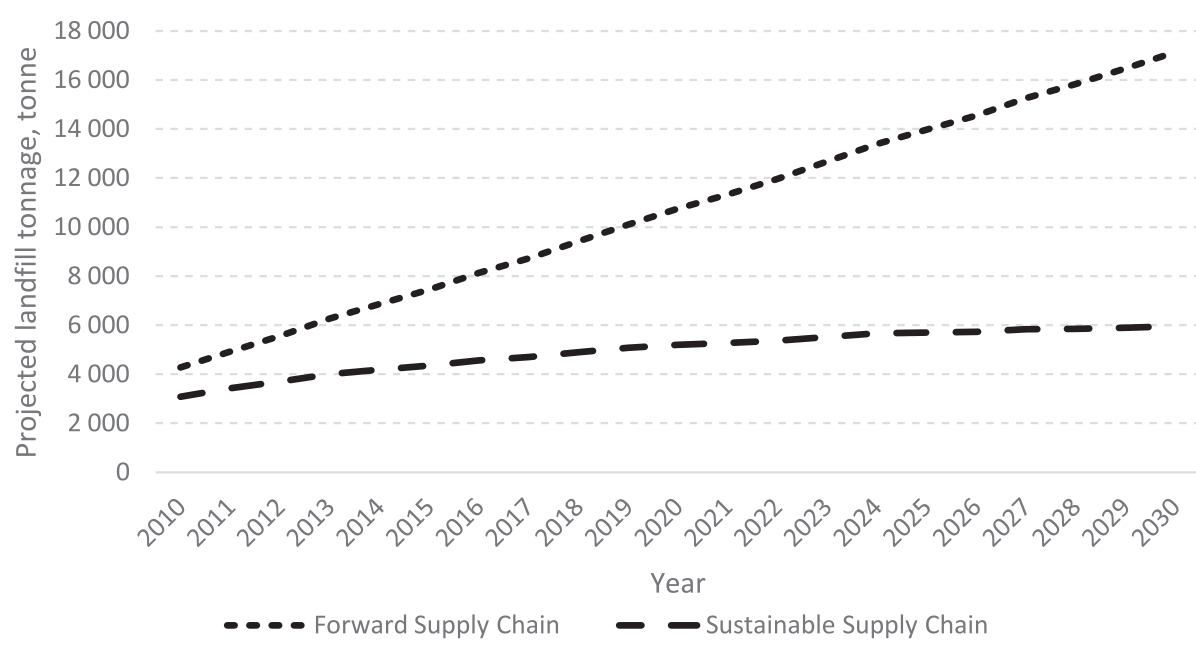

Fig. 8. Comparison between the forward supply chain and sustainable supply chain.

\section{Model Analysis}

Each of the supply chain model was run based on the same assumption and the outcomes were analyzed. It was found out that there was not much difference on the trend of total plastic wastes generated at landfill for both simulated open-loop and closed-loop supply chain. However, there was a large difference between forward supply chain and sustainable supply chain management (represented both open-loop and closed-loop supply chain) with $10 \%$ diversion rate. It was projected that with $10 \%$ diversion rate along the supply chain, the amount of plastic packaging waste can be significantly reduced by approximately $65 \%$. Fig. 8 below shown the gap between forward supply chain and sustainable supply chain.

Next, Analysis of variance (ANOVA) test was done to analyse whether there is any difference in the means for forward supply chain and sustainable supply chain, namely open-loop supply chain and closed-loop supply chain. The test was done to test the hypothesis, where the null hypothesis stated that there was no difference in means for forward supply chain $\left(\mu_{1}\right)$, open-loop supply chain $\left(\mu_{2}\right)$ and closed-loop supply chain $\left(\mu_{3}\right)$. Table 2 and Table 3 shows the results from the statistical analysis.

Hypothesis:

$\mathrm{H}_{0}=\mu_{1}=\mu_{2}=\mu_{3}$

$\mathrm{H}_{1}=$ at least one of the means is different

Conclusion, if $\mathrm{F}>\mathrm{F}$ crit, the null hypothesis would be rejected. In this case, $31.34>3.19$. Therefore, the null hypothesis was rejected, which means that the three populations were not all equal and at least one of the means was different.

Next, t-Test was carried out to determine whether the means for open loop supply chain and closed loop supply chain was equal. The null hypothesis for t-Test was set as the means of two populations were equal.

Table 4 shows the results from the t-Test for open loop $\left(\mu_{1}\right)$ and closed loop supply chain $\left(\mu_{2}\right)$.

Hypothesis:

$\mathrm{H}_{0}=\mu_{1}-\mu_{2}=0$ meaning the means of two population are equal.

$\mathrm{H}_{1}=\mu_{1}-\mu 2 \neq 0$

Conclusion, if $\mathrm{t}$-Stat $<-\mathrm{t}$ Critical two tail or $\mathrm{t}$ Stat $>t$ Critical two tail, the null hypothesis would be rejected. Results from the analysis indicated that $-2.0369<-0.0025<2.0369$. Therefore, the null hypothesis was accepted which indicated that the means of two populations were equal.

Subsequently, t-Test was once again done to test the null hypothesis that the variance of forward supply chain $\left(\mu_{1}\right)$ is equal to open loop supply chain $\left(\mu_{2}\right)$. Table 5 below shows the results of the t-Test for forward supply chain and open-loop supply chain.

Hypothesis:

$\mathrm{H}_{0}=\mu_{1}-\mu_{2}=0$ meaning the means of two population are equal.

$\mathrm{H}_{1}=\mu_{1}-\mu_{2} \neq 0$

Conclusion, if t-Stat $<-\mathrm{t}$ Critical two tail or t Stat $>$ t Critical two tail, the null hypothesis would be rejected. Outcomes from the analysis indicated

Table 2. Summary for single factor analysis of variance (ANOVA).

\begin{tabular}{|c|c|c|c|c|}
\hline Groups & Count & Sum & Average & Variance \\
\hline Forward & 17 & 160323 & 9430.764706 & 10601263.07 \\
\hline Open loop & 17 & 80432 & 4731.294118 & 687597.3456 \\
\hline Closed loop & 17 & 80444 & 4732 & 687603.75 \\
\hline
\end{tabular}


Table 3 ANOVA for forward, open loop and closed loop landfill data.

\begin{tabular}{|c|c|c|c|c|c|c|}
\hline Source of Variation & SS & df & MS & F & P-value & F crit \\
\hline Between Groups & 250259346.4 & 2 & 125129673.2 & 31.34 & $1.96 \mathrm{E}-09$ & 3.19 \\
\hline Within Groups & 191623426.6 & 48 & 3992154.721 & & & \\
\hline Total & 441882773 & 50 & & & & \\
\hline
\end{tabular}

Table 4. t-Test for open-loop and closed-loop landfill data.

\begin{tabular}{|c|c|c|}
\hline & Open-loop & Closed-loop \\
\hline Mean & 4731.294118 & 4732 \\
\hline Variance & 687597.3456 & 687603.75 \\
\hline Observations & 17 & 17 \\
\hline Pooled Variance & 687600.5478 & \\
\hline $\begin{array}{c}\text { Hypothesized Mean } \\
\text { Difference }\end{array}$ & 0 & \\
\hline df & 32 & \\
\hline $\mathrm{t}$ Stat & -0.002481839 & \\
\hline $\mathrm{P}(\mathrm{T}<=\mathrm{t})$ one-tail & 0.499017594 & \\
\hline $\mathrm{t}$ Critical one-tail & 1.693888748 & \\
\hline $\mathrm{P}(\mathrm{T}<=\mathrm{t})$ two-tail & 0.998035188 & \\
\hline $\mathrm{t}$ Critical two-tail & 2.036933343 & \\
\hline
\end{tabular}

that $\mathrm{t}-$ Stat $>\mathrm{t}$ Critical two tail, so the null hypothesis was rejected.

Lastly, it can be concluded that there were differences between forward supply chain and openloop and closed-loop supply chain. However, there is no difference between open-loop supply chain and closed loop supply chain, which indicated that the means for both open-loop and closed-loop supply chain is the same. In addition, the outcomes from the models
Table 5. t-Test results for forward supply chain and open-loop supply chain.

\begin{tabular}{|c|c|c|}
\hline & Forward & Open-loop \\
\hline Mean & 9430.764706 & 4731.294118 \\
\hline Variance & 10601263.07 & 687597.3456 \\
\hline Observations & 17 & 17 \\
\hline Pooled Variance & 5644430.206 & \\
\hline $\begin{array}{c}\text { Hypothesized Mean } \\
\text { Difference }\end{array}$ & 0 & \\
\hline $\mathrm{df}$ & 32 & \\
\hline $\mathrm{t}$ Stat & 5.76697867 & \\
\hline $\mathrm{P}(\mathrm{T}<=\mathrm{t})$ one-tail & $1.0666 \mathrm{E}-06$ & \\
\hline $\mathrm{t}$ Critical one-tail & 1.693888748 & \\
\hline $\mathrm{P}(\mathrm{T}<=\mathrm{t})$ two-tail & $2.1332 \mathrm{E}-06$ & \\
\hline $\mathrm{t}$ Critical two-tail & 2.036933343 & \\
\hline
\end{tabular}

indicated that both open-loop and closed-loop supply chain can drastically reduce the amount of plastic wastes from going into the landfill.

Fig. 9 shows the total tonnage of plastic waste going to the landfill based on the simulated model for the open and closed-loop supply chain. Total tonnage of plastic waste in landfill was projected at 5,722 tonnes in 2030 if the waste diversion rate was $10 \%$.

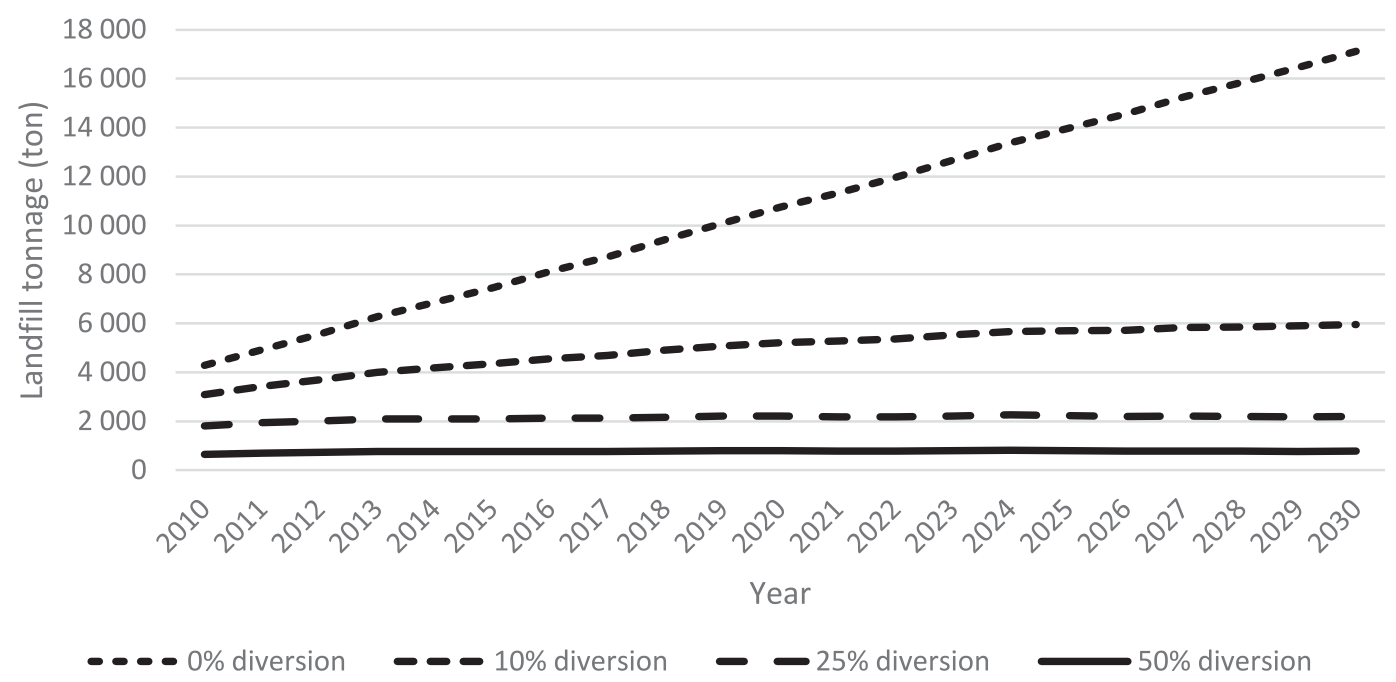

Fig. 9. Influence of different plastic waste diversion rate on landfill for open and closed-loop supply chain. 
If the diversion rate was $25 \%$, the tonnage of plastic waste was projected to drop to 2,190 tonnes and it further reduced to 777 tonnes if the diversion rate was $50 \%$. The difference in total tonnage of plastic wastes going to landfill for $10 \%$ waste diversion rate and $25 \%$ waste diversion rate was between 41.365 and $61.72 \%$ while the difference between $25 \%$ diversion rate and $50 \%$ diversion rate was quite constant with the average of $64 \%$. Total percentage drop between $10 \%$ diversion rate and $50 \%$ diversion rate was between $79 \%$ and $86 \%$.

It was concluded that there was difference in the means between forward supply chain, open-loop supply chain and closed-loop supply chain based on the ANOVA single factor analysis. Model analysis indicated that open loop supply chain and closed loop supply chain can significantly help to divert the plastic wastes from going to the landfill. However, there was no significant difference between the total tonnage of plastic wastes diverted for both open loop supply chain and closed loop supply chain.

\section{Conclusions}

Three system dynamics models had been developed in this study, which were forward supply chain management, open-loop supply chain management and closed-loop supply chain management. These models were created with Vensim PLE software, and model validation tests such as dimensional consistency and behavior reproduction were performed to ensure that the simulation results could be utilized to represent the real system. The simulation models's parameters and variables were derived from a literature review and information provided by key players in the plastic industry.

The models were analyzed using ANOVA to see if there was a difference between the forward, open-loop and closed-loop supply chains. Based on the ANOVA single factor analysis, it was determined that there was a difference between forward supply chain, open-loop supply chain and closed-loop supply chain management for plastic materials. According to the findings, both open-loop and closed-loop supply chains dramatically reduce the amount of plastic waste that ends up in landfills. When compared to open-loop and closed-loop supply chain management, the overall tonnage of plastic waste in landfill for forward supply chain management is much larger. However, there was no statistically significant difference on the overall amount of plastic wastes diverted from landfill for both closed-loop and open-loop supply chains, as well as used product inventory.

The difference between a $10 \%$ diversion rate and a $25 \%$ diversion rate ranged from $41 \%$ to $62 \%$, whereas the difference between a $25 \%$ diversion rate and a $50 \%$ diversion rate remained relatively steady at $64 \%$ on average. Total plastic wastes going to landfill was reduced by $79 \%$ to $86 \%$ with a $10 \%$ diversion and a $50 \%$ diversion rate. The outcomes of these analyses revealed that when the waste diversion rate increased, the growth rate of waste at landfill was dramatically reduced.

When determining the contribution of this research, it is important to recognise its limits. This research had the following limitations:

1. The scope of this study is limited to industrial waste management in the Klang Valley.

2. Obtaining feedback from the industry players is difficult. It was challenging to choose the right organization or person for the interview because just a few industry players have dedicated people to handle solid waste management.

3. The information provided by the interviewed parties, as well as official records published on their official corporate website and environmental reports, determine the availability of data for analysis.

4. Supply chain firms refuse to provide their operational costs since they are considered private and confidential. As a result, specific information on financial matters was unavailable.

In conclusion, this research has provided an overview of Malaysia's existing plastic waste management practices as well as the impact of various supply chain management strategies on the material recovery rate. More research is needed in order to enhance the recycling rate of plastic wastes. Future research could combine Industry Revolution (IR) 4.0 technologies such as internet of things, cyber-physical system, sensors and big data implementation, which have a strong potential to improve plastic industry's sustainable supply chain management.

\section{Acknowledgments}

This work was supported by SEGi University [Grant number: SEGiIRF/2015-05/FOEBE-15/89]; and the funding from Malaysia Government on the MyBrain15 for $\mathrm{PhD}$ program.

\section{Conflict of Interest}

The authors declared no conflicts of interest.

\section{References}

1. NKWACHUKWU O.I., CHIMA C.H., IKENNA A.O., ALBERT L. Focus on potential environmental issues on plastic world towards a sustainable plastic recycling in developing countries. International Journal of Industrial Chemistry, 4 (1), 1, 2013.

2. SINGH N., HUI D., SINGH R., AHUJA I.P.S., FEO L., FRATERNALI F. Recycling of plastic solid waste: A state of art review and future applications. Composites Part B: Engineering, 115, 409, 2017. 
3. BROOKS A.L., WANG S., JAMBECK J.R. The Chinese import ban and its impact on global plastic waste trade. Science advances, 4 (6), eaat $0131,2018$.

4. GOURMELON G. Global plastic production rises, recycling lags. Vital Signs, 22, 91, 2015.

5. GEYER R., JAMBECK J.R., LAW K.L. Production, use, and fate of all plastics ever made. Science advances, 3 (7), e1700782, 2017.

6. GU F., GUO J., ZHANG W., SUMMERS P.A., HALL P. From waste plastics to industrial raw materials: A life cycle assessment of mechanical plastic recycling practice based on a real-world case study. Science of the total environment, 601, 1192, 2017.

7. HUYSMAN S., DEBAVEYE S., SCHAUBROECK T., DE MEESTER S., ARDENTE F., MATHIEUX F., DEWULF J. The recyclability benefit rate of closed-loop and openloop systems: A case study on plastic recycling in Flanders. Resources, Conservation and Recycling, 101, 53, 2015.

8. BEZAMA A. Let us discuss how cascading can help implement the circular economy and the bio-economy strategies. SAGE Publications Sage UK: London, England, 593, 2016.

9. Industrial ecology: An introduction. Available online: http://www.umich.edu/ nppcpub/resources/compendia/ INDEpdfs/INDEintro.pdf (accessed on 12 April 2021).

10. GOLROUDBARY S.R., ZAHRAEE S.M. System dynamics model for optimizing the recycling and collection of waste material in a closed-loop supply chain. Simulation Modeling Practice and Theory, 53, 88, 2015.

11. VLACHOS D., GEORGIADISP., IAKOVOU E. A system dynamics model for dynamic capacity planning of remanufacturing in closed-loop supply chains. Computers \& Operations Research, 34 (2), 367, 2007.

12. RODRIGUES L., FARAHNAZ M., DEEPAK R., VASANTH K. System dynamics model for remanufacturing in closed loop supply chains. In the $30^{\text {th }}$ International Conference of the System Dynamics Society, St. Gallen, New Zealand, 1, 2012.

13. Survey on Solid Waste Composition, Characteristics \& Existing Practice of Solid Waste Recycling in Malaysia. Available online: https://jpspn.kpkt.gov.my/resources/ index/user_1/Sumber_Rujukan/kajian/Final_Report_ REVz.pdf (available online 12 April 2021).

14. Solid waste management in Malaysia: The way forward. Available online: http://ensearch.org/wp-content/ uploads/2012/07/Paper-13.pdf (available online 12 April 2021).

15. Why the world's recycling system stopped working. Available online: https://www.ft.com/content/360e2524d71a-11e8-a854-33d6f82e62f8 (accessed on 20 April 2021).

16. SHI J., ZHANG C., CHEN W.-Q. The expansion and shrinkage of the international trade network of plastic wastes affected by China's waste management policies. Sustainable Production and Consumption, 25, 187, 2021

17. WANG W., THEMELIS N.J., SUN K., BOURTSALAS A.C., HUANG Q., ZHANG Y., WU Z. Current influence of China's ban on plastic waste imports. Waste Disposal \& Sustainable Energy, 1 (1), 67, 2019.

18. CETINKAYA B., CUTHBERTSON R., EWER G., KLAAS-WISSING T., PIOTROWICZ W., TYSSEN C. Sustainable Supply Chain Management, $1^{\text {st }}$ ed.; SpringerVerlag: Heidelberg, Germany, 3, 2011

19. CROXTON K.L., GARCÍA-DASTUGUE S.J., LAMBERT, D.M., ROGERS D.S. The supply chain management processes. The International Journal of Logistics Management, 12 (2), 13, 2001.

20. WAINWRIGHT J., MULLIGAN M. Environmental Modeling, $2^{\text {nd }}$ ed.; John Wiley and Sons: Oxford, United Kingdom, 335, 2002.

21. Bridging economy and ecology: a circular economy approach to sustainable supply chain management. Available online: https://core.ac.uk/download/ pdf/301363372.pdf (accessed on 20 April 2021).

22. NESKOVIC MARKIC D., STEVANOVIC CARAPINA H., BJELIC D., STOJANOVIC BJELIC L., ILIC P., SOBOT PESIC Z., KIKANOVIC O. Using material flow analysis for waste management planning. Polish Journal of Environmental Studies, 28 (1), 255, 2018.

23. GEYER R., JACKSON T. Supply loops and their constraints: the industrial ecology of recycling and reuse. California Management Review, 46 (2), 55, 2004

24. BRANDENBURG M., GOVINDAN K., SARKIS J., SEURING S. Quantitative models for sustainable supply chain management: Developments and directions. European Journal of Operational Research, 233 (2), 299, 2014.

25. WANG G., GUNASEKARAN A. Modeling and analysis of sustainable supply chain dynamics. Annals of Operations Research, 250 (2), 521, 2017.

26. NAKATANI J. Life cycle inventory analysis of recycling: mathematical and graphical frameworks. Sustainability, 6 (9), 6158, 2014.

27. A study of plastic recycling supply chain. Available online: https://www.ciltuk.org.uk/portals/0/documents/pd/ seedcornwong. pdf (accessed on 20 April 2021).

28. STERMAN J. System Dynamics: Systems Thinking and Modeling for a Complex World, $1^{\text {st }}$ ed.; McGraw-Hill: New York, United States of America, 135, 2000.

29. AnyLogic 7 in three days. Available online: https://www. anylogic.com/resources/books/free-simulation-book-andmodeling-tutorials/ (accessed on 20 April 2021).

30. IANDOLO F., BARILE S., ARMENIA S., CARRUBBO L. A system dynamics perspective on a viable systems approach definition for sustainable value. Sustainability Science, 13 (5), 1245, 2018.

31. XU Y., SZMEREKOVSKY J. System dynamic modeling of energy savings in the US food industry. Journal of Cleaner Production, 165, 13, 2017.

32. GRAEDEL T.E., ALLENBY B.R. Industrial Ecology, $2^{\text {nd }}$ ed.; Pearson Education Inc: Upper Saddle River, Prentice Hall, 2002.

33. System dynamics modeling of closed loop supply chain systems for evaluating system improvement strategies. Available online: https://ap-st01.ext.exlibrisgroup.com/ 61RMIT INST/storage/alma/B3/48/12/89/24/A3/ED/78/ $\mathrm{CC} / \mathrm{C} 8 / 14 / 12 / \mathrm{CE} / \mathrm{A} 1 / \mathrm{BA} / 51 /$ Poles.pdf?Expires $=16255091$ 36\&Signature $=$ QtLNUOvCo21gU7SY5EarTq8dZwbG8 w1lnbSYPdXw6ER VQ xZE6AgfrMI G6rFBoruXwO mW0PR1EjgLyYYUkwZQcojjSa5Zsz-V34T 7X12vovIkSu4b0zQS1ObT0tQQq BIwGszEueW TVDpjefX EQou7wx InsnOA9emKI-ADzNH0UsvTYOiP4Qu6zGZoFx3NwmcU25j1L79Kx-KBOQ0Vd1 wcEATGSdz 118oVVGf5pnXDqme8jaDluK6TXz4Ou37Fj2sPtutsTU0 ysCGvguXAFn33zS3G1U8W-GSCSI79mnUAMGiwubo TVzkeGj01r6g 5pkUXZbKJiiYLgKciyQg_\&Key-PairId=APKAJ72OZCZ36VGVASIA (accessed on 20 April 2021).

34. NARA E.O.B., DA COSTA M.B., BAIERLE I.C., SCHAEFER J.L., BENITEZ G.B., DO SANTOS L.M 
A.L., BENITEZ L.B. Expected impact of industry 4.0 technologies on sustainable development: A study in the context of Brazil's plastic industry. Sustainable Production and Consumption, 25, 102, 2021.
35. STRAKA M., TAUŠOVÁ M., ROSOVÁ A., CEHLÁR M., KAČMÁRY P., SISOL M., FARKAS C. Big data analytics of a waste recycling simulation logistics system. Polish Journal of Environmental Studies, 29 (3), 2355, 2020. 
